\title{
Functional outcome in patients with unstable distal radius fractures, volar locking plate versus external fixation: a meta-analysis
}

\author{
Monique M. J. Walenkamp • Abdelali Bentohami • M. Suzan H. Beerekamp • \\ Rolf W. Peters • Remy van der Heiden · J. Carel Goslings • \\ Niels W. L. Schep
}

Received: 7 March 2013/Accepted: 21 July 2013/Published online: 28 July 2013

(c) The Author(s) 2013. This article is published with open access at Springerlink.com

\begin{abstract}
The aim of this study was to compare bridging external fixation with volar locked plating in patients with unstable distal radial fractures regarding functional outcome. A systematic search was performed in the Cochrane Central Register of Controlled Trials, Medline and EMBASE. All randomized controlled trials that compared bridging external fixation directly with volar locked plating in patients with distal radial fractures were considered. Three reviewers extracted data independently from eligible studies using a data collection form. Studies in which the primary endpoint was measured on the disabilities of the arm shoulder and hand (DASH) score at 3, 6 and 12 months were included in the analysis. To this end, mean
\end{abstract}

M. M. J. Walenkamp (凹) A A. Bentohami .

M. S. H. Beerekamp · R. W. Peters · J. C. Goslings ·

N. W. L. Schep

Trauma Unit, Department of Surgery, Academic Medical Center

Amsterdam, Po Box 22660, 1100 DD Amsterdam,

The Netherlands

e-mail: m.m.walenkamp@amc.nl

A. Bentohami

e-mail: a.bentohami@amc.nl

M. S. H. Beerekamp

e-mail: m.s.beerekamp@amc.nl

R. W. Peters

e-mail: r.w.peters@amc.nl

J. C. Goslings

e-mail: j.c.goslings@amc.nl

N. W. L. Schep

e-mail: n.w.schep@amc.nl

R. van der Heiden

Faculty of Medicine, Erasmus Medical Center, Rotterdam,

The Netherlands

e-mail: remyvanderheiden@gmail.com scores and standard deviations were extracted. The software package Revman 5 provided by the Cochrane Collaboration was used for data analysis. Three studies involving 174 patients were analyzed. Ninety patients were treated with an (augmented) bridging external fixator and 84 with a volar locking plate. Data were analyzed with the random effects model. The robustness of the results was explored using a sensitivity analysis. Patients treated with a volar locking plate showed significantly lower DASH scores at all times. A difference of $16(p=0.006)$, six $(p=0.008)$ and eight points $(p=0.06)$ was found at 3,6 and 12 months follow-up, respectively. Patients treated with a volar locking plate showed significantly better functional outcome throughout the entire follow-up. However, this difference was only clinically relevant during the early postoperative period ( 3 months).

Keywords Meta-analysis - Unstable distal radius fracture $\cdot$ Volar locking plate $\cdot$ Bridging external fixator $\cdot$ Functional outcome

\section{Introduction}

Fractures of the distal radius are common and account for an estimated $17 \%$ of all fractures diagnosed [1, 2]. Twothirds of these fractures are displaced and require reduction [3]. Several treatment modalities have been advocated, and decision-making is mainly based on fracture type $[4,5]$.

One possible surgical treatment method is bridging external fixation. This technique relies on ligamentotaxis to obtain and maintain fracture alignment [6]. However, since the introduction of locking plates, open reduction and internal fixation (ORIF) has become increasingly popular in surgical reduction [7]. This technique provides 
immediate stable fixation that allows early mobilization [5, 8] and may result in a more rapid recovery and improved regain of function [9]. Conversely, bridging external fixation augmented (with or without additional Kirschner wires) is a less demanding, less invasive and faster procedure. Excellent results have been described for both techniques [10-15]. However, no conclusive evidence has been published favoring ORIF with a volar locking plate over bridging external fixation or vice versa [16].

Margaliot et al. [11] conducted a meta-analysis of studies published between 1980 and 2004 on external and internal fixation of distal radial fractures. They concluded there was not sufficient evidence to support the use of ORIF over external fixation. However, outcome data from a large variety of different techniques of internal fixation were pooled. Studies on both locking and nonlocking implants were included resulting in considerable heterogeneity across studies [11]. More recently, Wei et al. [17] performed a similar meta-analysis comparing functional outcome at 1 year in patients with unstable distal radius fractures. The authors pooled data from 12 randomized and nonrandomized trials on seven different techniques of internal fixation. A secondary subgroup analysis of four studies for volar locking plates revealed a significant difference on the disabilities of the arm shoulder and hand (DASH) score in favor of this technique. Unfortunately, exact DASH scores could not be reported, and therefore, clinical relevance of these differences is difficult to evaluate [18]. Moreover, this analysis included one retrospective study [19] and one trial that compared volar locking plates with closed reduction and percutaneous pinning [20]. The authors emphasized that their results were tempered by a substantial heterogeneity present across studies [17]. However, their significant findings justify further examination regarding the benefits of volar locking plates.

Recent studies on ORIF with volar locking plate have described most benefit in the early postoperative period $[21,22]$. In addition to improved functional results at 1 year, a more rapid recovery is of clinical interest as well. Therefore, the primary aim of this meta-analysis was to compare bridging external fixation with volar locked plating in patients with unstable distal radius fractures, regarding functional outcome as measured on the DASH score, at 3, 6 and 12 months follow-up. The secondary aim was to compare grip strength, flexion and extension and radiological parameters at 1 year follow-up.

\section{Materials and methods}

The present study was reported according to the PRISMA guidelines (Preferred Reporting Items for Systematic reviews and Meta-Analyses) [23].
Eligibility criteria

All randomized clinical trials that compared (augmented) bridging external fixation with volar locking plates in adult patients with unstable distal radial fractures were considered. Publication language was restricted to English and Dutch. Studies that did not clearly define the patient population (unstable distal radius fracture) and thus did not the fine the indication for surgery were not included. Trials that compared different fixation techniques or other implants were not included either. Studies that reported functional outcome on the disability of arm, shoulder and hand score at 3, 6 and 12 months follow-up were included.

Types of outcome measures

The primary outcome measure of this meta-analysis was a functional outcome defined by the DASH score at 3,6 and 12 months follow-up. The DASH score is a validated 30-item, self-report questionnaire designed to measure physical function and symptoms in patients with musculoskeletal disorders of the upper limb. Lower scores indicate a better functional outcome. The total scale score ranges from 0 (no disability) to 100 (most severe disability) [24]. The secondary outcome measures of this review were as follows: grip strength measured as a percentage of the uninjured side, flexion and extension in degrees, and radiological parameters including radial inclination, volar tilt, ulnar variance and radial length at a minimal of 1 year follow-up.

\section{Data sources}

We conducted a search for three electronic databases: Cochrane Central Register of Controlled Trials, Medline and EMBASE in March 2013. In order not to miss recently published literature, the use of MESH terms was avoided. The complete search strategy is depicted in Table 1. Additionally, a cross-reference check for the articles of interest was performed.

Study selection

All titles that resulted from the search strategy described above were screened independently by three reviewers. Publications reporting on completely different subjects were identified and excluded. If titles did not provide sufficient information, abstracts were examined. Cohort studies, case studies, comments and current (management) views were excluded. Eligibility with regard to the in- and exclusion criteria of the remaining articles was subsequently assessed based on full text. Disagreement was resolved by means of discussion which included a second 
Table 1 Search strategy

Medline

((((distal[Title/Abstract]) AND fracture*[Title/Abstract]) AND ((radius[Title/Abstract]) OR radial[Title/Abstract])) OR (((((colles' fracture*[Title/Abstract]) OR colles fracture*[Title/Abstract]) OR smith fracture*[Title/Abstract]) OR barton fracture*[Title/Abstract]) OR wrist fracture*[Title/Abstract])) AND (((volar[Title/Abstract]) OR palmar[Title/Abstract]) OR palmer[Title/Abstract]) AND ((((external fix*[Title/Abstract]) OR fixation ext*[Title/Abstract]) OR fixateur ext*[Title/Abstract]) OR fixator ext*[Title/Abstract])

\section{EMBASE}

((((distal.ti,ab) AND fracture*.ti,ab) AND ((radius.ti,ab) OR radial.ti,ab)) OR (((((colles’ fracture*.ti,ab) OR colles fracture*.ti,ab) OR smith fracture*.ti,ab) OR barton fracture*.ti,ab) OR wrist fracture*.ti,ab)) AND (((volar.ti,ab) OR palmar.ti,ab) OR palmer.ti,ab) AND ((((external fix*.ti,ab) OR fixation ext*.ti,ab) OR fixateur ext*.ti,ab) OR fixator ext*.ti,ab)

Cochrane Central Register of Controlled Trials

(distal:ti,ab,kw and fracture*:ti,ab,kw) AND (radius:ti,ab,kw or radial:ti,ab,kw or "Colles' fracture*”:ti,ab,kw or "Colles fracture*”:ti,ab,kw or "Barton's fracture":ti,ab,kw or smith fracture*:ti,ab,kw or "Smith's fracture*":ti,ab,kw or wrist fracture*:ti,ab,kw) AND ("volar":ti,ab,kw or "palmar":ti,ab,kw or "Palmer":ti,ab,kw) AND (extern*:ti,ab,kw or "fixation":ti,ab,kw or "fixator":ti,ab,kw or fixat*:ti,ab,kw)

trauma surgeon with a master in clinical epidemiology (NS).

\section{Data extraction}

Three reviewers extracted data independently from eligible studies using a data collection form. Items include study type, number of subjects, patient characteristics, fracture types, treatment method, length of follow-up and outcome measures. Means and standard deviations were extracted for continuous outcomes or calculated from confidence intervals. Studies in which these values were not reported were excluded [15]. If multiple treatment types were studied, only data regarding patients treated with bridging external fixation or ORIF were extracted. Risk of bias was assessed using the GRADE guidelines [25].

\section{Data synthesis}

The software package Revman 5 provided by the Cochrane Collaboration was used for data analysis [26]. The mean differences in DASH scores between treatment groups at 3 , 6 and 12 months were calculated with 95 percent confidence intervals. The random effects model was used to pool data [27]. Heterogeneity was explored using the chisquare test, with significance set at $p<0.1$. For quantification, $I^{2}$ was used with values less than $30 \%$ indicating low heterogeneity $[28,29]$.

\section{Sensitivity analysis}

The stability of the results regarding the DASH scores at 3, 6 and 12 months was tested using a sensitivity analysis under different assumptions. Sensitivity analyses were performed based on methodological quality of the included studies and the meta-analytic model. In addition, the robustness of results was explored by consecutively excluding one study.

\section{Results}

\section{Literature search}

The search yielded 197 results, three of which met our inclusion criteria (Fig. 1) [30-32]. In total, 174 patients were included, of which 90 were treated with an (augmented) bridging external fixator and 84 patients with a volar locking plate.

\section{Description of included studies}

The study characteristics are summarized in Table 2.

Egol et al. [31] randomized 88 patients with an unstable distal radial fracture to undergo either bridging external fixation (EBI, Parsippany, New Jersey or Stryker, Mahwah, New Jersey) and a K-wire construct or ORIF with a volar locking plate (Hand Innovations, Miami, Florida or Stryker). Inclusion criteria were as follows: loss of reduction following closed reduction and cast immobilization, open fractures or anticipated fracture instability. Criteria for an adequate reduction measured on conventional X-rays included residual dorsal angulation of $<10^{\circ}$ and loss of radial height of $<2 \mathrm{~mm}$. Randomization was performed with a random number generator. The result was handed in a sealed envelope to the treating physician. Seventy-seven patients were included in the analysis, 38 received external fixation with supplementary K-wires and 39 a volar locking plate. DASH scores were reported at a follow-up of 3,6 and 12 months.

Wei et al. [33] randomized 46 patients with an unstable distal radius fracture to be treated with augmented external fixation $(n=22)$, a volar locking plate $(n=12)$ or a radial locking column plate $(n=12)$. Fractures were considered unstable if fracture fragments were redisplaced following closed reduction and cast immobilization, or if three of the following criteria were met: dorsal angulation of $>20^{\circ}$, dorsal comminution, an intra-articular fracture, an 

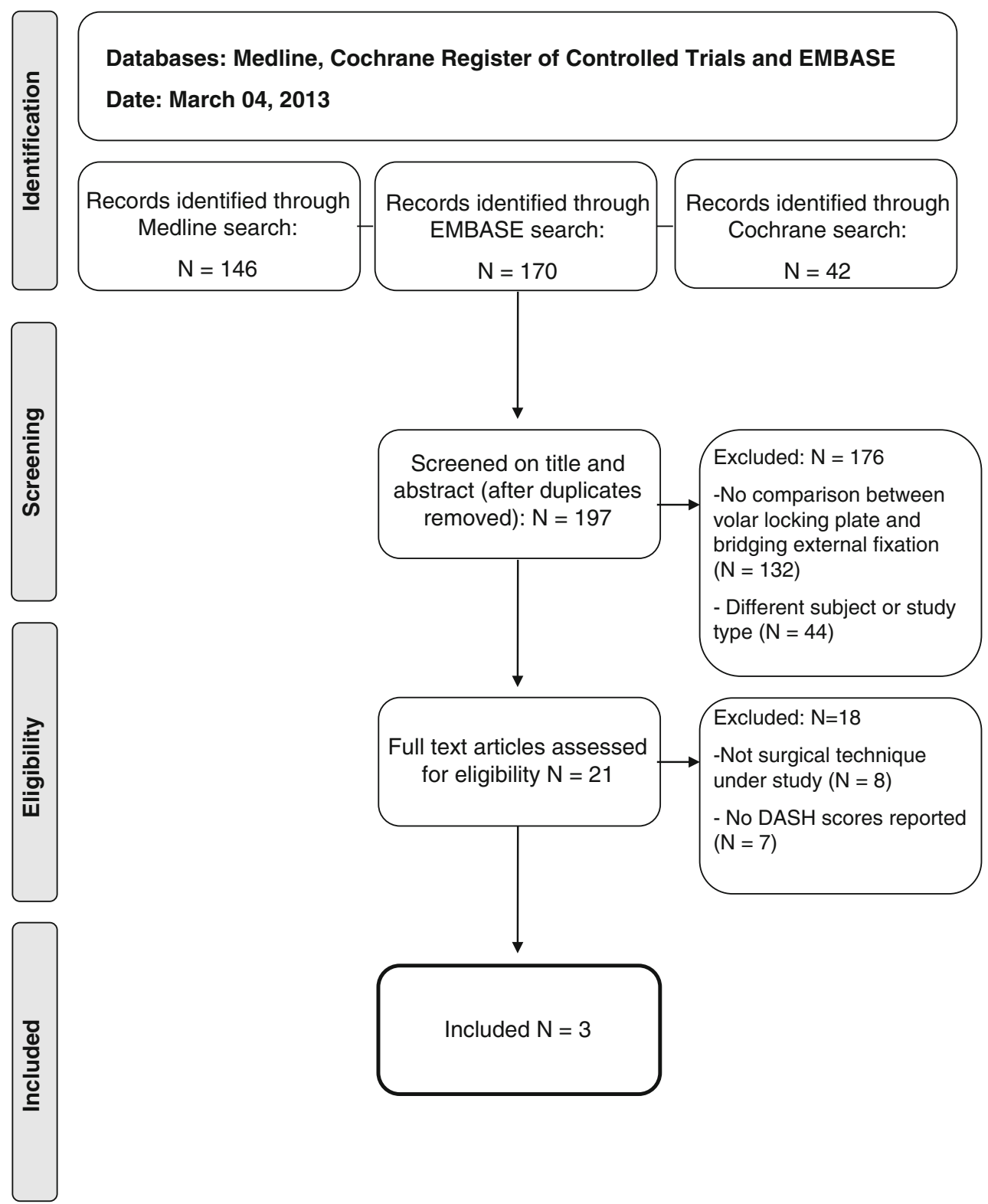

Fig. 1 Flow diagram of in- and excluded studies

Table 2 Details of included studies

\begin{tabular}{|c|c|c|c|c|c|c|c|c|}
\hline \multirow[t]{2}{*}{ Author } & \multirow{2}{*}{$\begin{array}{l}\text { Study } \\
\text { design }\end{array}$} & \multirow{2}{*}{$\begin{array}{l}\text { AO classification } \\
\text { of included fractures }\end{array}$} & \multicolumn{2}{|c|}{ Sample size } & \multirow{2}{*}{$\begin{array}{l}\text { Mean age } \\
\text { (years) }\end{array}$} & \multirow[t]{2}{*}{ Country } & \multirow{2}{*}{$\begin{array}{l}\text { Year } \\
\text { published }\end{array}$} & \multirow[t]{2}{*}{ DASH reported at } \\
\hline & & & Fix ex & Vo. Lo. plate & & & & \\
\hline Egol et al. & $\mathrm{RCT}^{\mathrm{a}}$ & $\mathrm{A}, \mathrm{B}, \mathrm{C}$ & 38 & 39 & 51 & USA & 2008 & $3,6,12$ months \\
\hline Wei et al. & $\mathrm{RCT}$ & $\mathrm{A} 3, \mathrm{C} 1, \mathrm{C} 2, \mathrm{C} 3$ & 22 & 12 & 57 & USA & 2009 & $3,6,12$ months \\
\hline Wilcke et al. & $\mathrm{RCT}$ & $\mathrm{A}, \mathrm{C} 1$ & 30 & 33 & 56 & Sweden & 2011 & $3,6,12$ months \\
\hline
\end{tabular}

${ }^{a}$ Randomized controlled trial

associated ulnar styloid fracture or age $>60$ years. Patients were randomized into three study arms in two phases. First, patients were assigned to be treated with augmented external or internal fixation. During a second randomization, the patients who had been assigned to receive internal fixation were further randomized to be treated with either a 
A

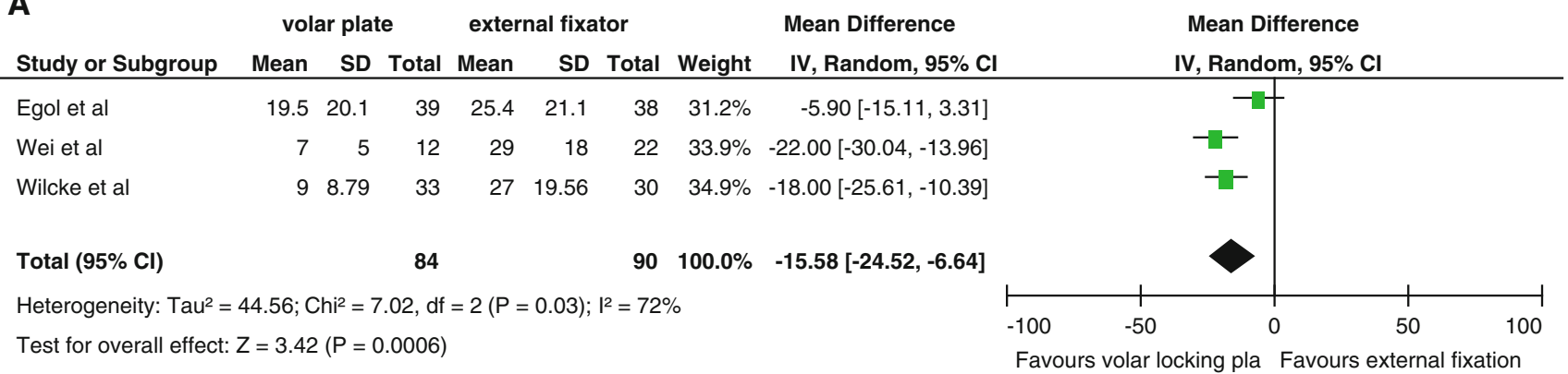

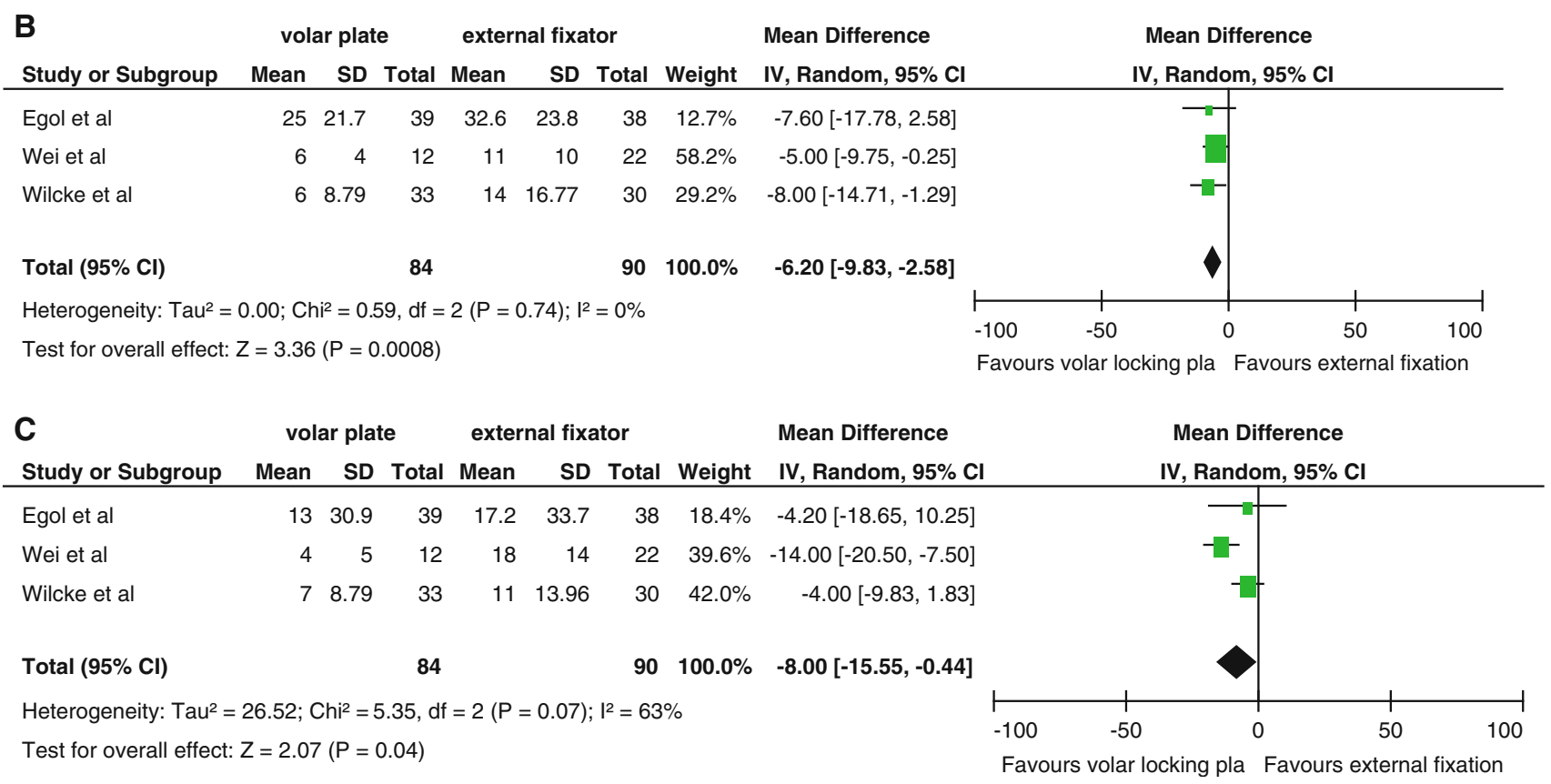

Fig. 2 DASH scores at 3,6 and 12 months. a Table and forest plot illustrating functional outcome based on DASH scores comparing external fixation with a volar locking plate at 3 months with a random effects model. b Table and forest plot illustrating functional outcome based on DASH scores comparing external fixation with a volar locking plate at 6 months with a random effects model. c Table and forest plot illustrating functional outcome based on DASH scores comparing external fixation with a volar locking plate at 12 months with a random effects model. $S D$ standard deviation, $C I$ confidence interval, $d f$ degrees of freedom, $I V$ inverse variance

\begin{tabular}{|c|c|c|c|c|c|c|c|}
\hline \multirow[b]{2}{*}{ Study or Subgroup } & \multicolumn{3}{|c|}{ external fixation } & \multicolumn{3}{|c|}{ volar plate } & \multirow[b]{2}{*}{ Weight } \\
\hline & Mean & SD & Total & Mean & SD & Total & \\
\hline Egol et al & 17 & 2.6 & 38 & 23 & 6.5 & 39 & $62.6 \%$ \\
\hline Wei et al & -1.9 & 8.4 & 22 & 4 & 2 & 12 & $22.3 \%$ \\
\hline Wilcke et al & -11 & 11.18 & 30 & -7 & 5.86 & 33 & $15.2 \%$ \\
\hline Total $(95 \% \mathrm{Cl})$ & & & 90 & & & 84 & $100.0 \%$ \\
\hline
\end{tabular}

Fig. 3 Volar tilt. Table and forest plot illustrating radiographic outcome based on volar tilt comparing external fixation with a volar locking plate at 12 months with a random effects model. The found difference of six degrees indicates a more accurate anatomical

volar locking (EBI OptiLock, Parsippany, New Jersey) or a radial locking column plate. Randomization was done by computer-generated allocation using sealed, opaque

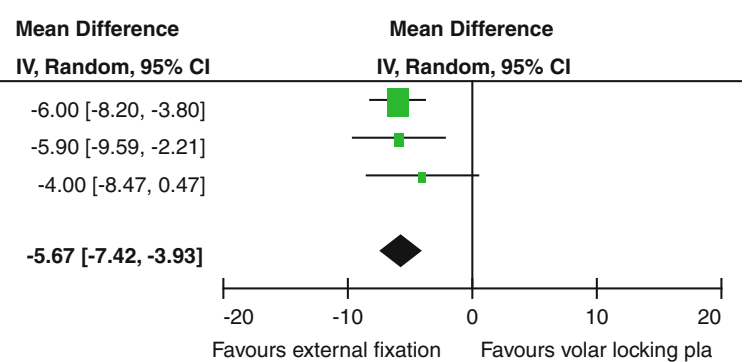

reconstruction of the volar tilt after treatment with a volar locking plate. $S D$ standard deviation, $C I$ confidence interval, $d f$ degrees of freedom, $I V$ inverse variance

envelopes. Only data on patients treated with an external fixator or with a volar locking plate were included in this meta-analysis. Treatment with external fixation (Hoffmann 
II Compact, Stryker) was augmented with K-wires in all patients, additional small buttress plates $(n=2)$ or filling of the metaphyseal void with cancellous bone allograft ( $n=4)$ as deemed appropriate by the surgeon. Two patients who had originally been assigned to be treated with a volar locking plate received additional fixation with a dorsal plate, and four patients received supplemental bone grafting following fixation with a volar locking plate. These patients were included in the analysis in the group they were originally assigned to. DASH scores were reported at a follow-up of 3, 6 and 12 months.

Wilcke et al. [32] randomized 63 patients under the age of 70 into volar locking plating $(n=33)$ or bridging external fixation $(n=30)$. Only dorsally displaced AO type $\mathrm{A}$ and $\mathrm{C} 1$ fractures with an axial shortening of $\geq 4 \mathrm{~mm}$ or a dorsal angulation of $\geq 20^{\circ}$ were included. Randomization was performed by a sealed envelope procedure. Randomization was conducted in blocks of 20 with age stratification set on 50 years. Patients were treated with a volar locking plate (Königsee; Swemac, Sweden) or an external fixator (Hoffmann II Compact, Stryker). In one patient, additional augmentation with a K-wire was performed. DASH scores were reported at a follow-up of 3, 6 and 12 months.

\section{Methodological quality}

The methodological quality of the included randomized controlled trials was moderate according to the guidelines of the GRADE working group [25]. All studies described the process of allocation concealment. Wei et al. randomized their patients into three study arms in two phases resulting in three treatment groups with unequal numbers of subjects. Patients were not blinded since the treatment involved a surgical procedure. Completion of follow-up at 1 year was $78 \%$ in Wei's study and $100 \%$ in the two other included studies.

In the study by Wei et al., all patients were analyzed based on the intention to treat principle. Egol et al. did not clearly describe crossover to other treatment arms and the type of analysis applied. In the study by Wilcke, one patient in the external fixator group was reoperated and received a supplementary volar plate. This patient was analyzed in the external fixator treatment arm. Power calculations were done for all three trials.

Functional and radiological outcome

At 3 months follow-up, there was a significant difference of 16 points in DASH score favoring the locking plate (95\% CI -24.52, -6.64). At 6 and 12 months, we found a significant difference of $6(95 \%$ CI $-9.83,-2.58)$ and eight points $(95 \%$ CI $-15.55,-0.44)$, respectively (Fig. 2a-c).

A significant difference in volar tilt was observed in favor of treatment with a volar locking plate (Fig. 3). No significant differences were demonstrated in the other secondary outcomes (Table 3).

\section{Sensitivity analysis}

Based on methodological quality, the study by Egol et al. was first excluded since they used a per protocol analysis. Subsequently, the trial by Wei et al. was excluded because of their considerable lost to follow-up. These analyses did not alter the findings or conclusions; all differences remained significant. This was similar when the metaanalytic model was changed. Considerable heterogeneity was found in the analysis of DASH score at 3 and 12 months. Data were homogenous for the DASH score at

Table 3 For the secondary outcomes such as grip strength, flexion, extension, radial inclination, ulnar variance and radial length, no significant differences were demonstrated

\begin{tabular}{llc}
\hline Outcome & $\begin{array}{l}\text { Number of } \\
\text { studies }\end{array}$ & Mean difference \\
\hline $\begin{array}{l}\text { Grip strength as percentage } \\
\text { of uninjured side }\end{array}$ & 3 & $-1.73(-12.27,15.73)$ \\
$\begin{array}{l}\text { Flexion (degrees) } \\
\text { Extension (degrees) }\end{array}$ & 2 & $0.44(-4.66,5.53)$ \\
Radial inclination (degrees) & 2 & $4.46(-5.21,14.14)$ \\
Ulnar variance (mm) & 3 & $-2.06(-4.6,0.49)$ \\
Radial length (mm) & 3 & $-0.086(1.82,0.10)$ \\
\hline
\end{tabular}

Table 4 Complications

\begin{tabular}{|c|c|c|}
\hline Complication & $\begin{array}{l}\text { ORIF with volar } \\
\text { locking plate }(N)\end{array}$ & $\begin{array}{l}\text { Bridging external } \\
\text { fixator }(N)\end{array}$ \\
\hline Pin tract infection & & 9 \\
\hline Deep infection & 1 & \\
\hline $\begin{array}{l}\text { Ruptured extensor/flexor } \\
\text { pollicis longus tendon }\end{array}$ & 3 & 1 \\
\hline CRPS I $^{\mathrm{a}}$ & & 3 \\
\hline Nonunion & 1 & 1 \\
\hline Painful retained hardware & 4 & \\
\hline $\mathrm{CTS}^{\mathrm{b}}$ & 2 & \\
\hline $\begin{array}{l}\text { Tenolysis for postoperative } \\
\text { stiffness }\end{array}$ & & 1 \\
\hline Malunion & & 4 \\
\hline Tendinitis & 1 & 1 \\
\hline Total & $17 / 84(20 \%)$ & $23 / 90(26 \%)$ \\
\hline
\end{tabular}

${ }^{a}$ Complex regional pain syndrome type 1

b Carpal tunnel syndrome 


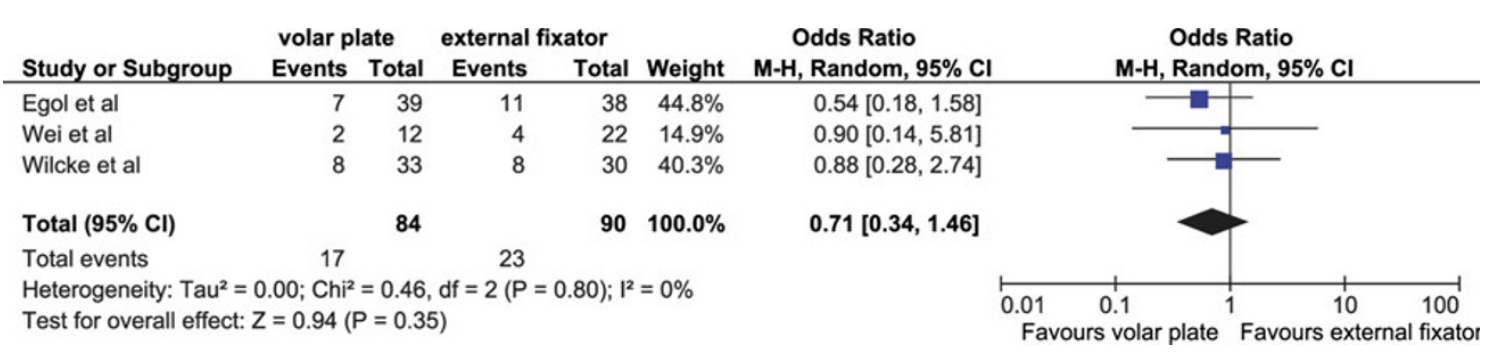

Fig. 4 Complications. Table and forest plot illustrating the complication rate comparing treatment with external fixation with a volar locking plate with a random effects model. $C I$ confidence interval, $d f$ degrees of freedom, $M-H$ Mantel-Haenszel

6 months $\left(I^{2}=0 \%\right)$. When the study by Egol et al. was excluded, data were homogenous $\left(I^{2}=0 \%\right)$ for the analysis of DASH score at 3 months as well. The same was witnessed for the DASH score at 12 months when the trial by Wei et al. was excluded.

\section{Complications}

A complication rate of $26 \%$ in the external fixator group and $20 \%$ in the volar locking plate group was found (Table 4). These differences were not significant (Fig. 4).

\section{Discussion}

This meta-analysis revealed a better functional outcome in patients with unstable distal radius fractures treated with a volar locking plate compared with (augmented) external fixation at 3, 6 and 12 months follow-up. Patients treated with a volar locking plate showed faster rehabilitation reflected in a 16-point difference in DASH score at 3 months. This difference subsided at 6 and 12 months to six and eight points, respectively.

However, in order to fully appreciate these finding, the clinical relevance of the differences in DASH scores should be taken into consideration. The minimal clinically important difference is the smallest difference in an outcome score that a patient perceives as beneficial. In patients with wrist pathology, the minimal clinically important difference in DASH score ranges between 10 points and 15 points [34, 35]. Therefore, functional outcome at 3 months can be considered to be both significantly better and clinically relevant for patients treated with a volar locking plate.

Although considerable heterogeneity was found in the analysis of DASH scores at 3 and 12 months, the differences remained significant under the sensitivity analyses. No clinical or methodological issues could be identified explaining this heterogeneity.

Another significant difference between treatment methods was a slightly improved anatomical restoration of the volar tilt in the ORIF group. The mean difference between external fixation and volar locking plate was six degrees, which indicates a more accurate anatomical reconstruction. Nevertheless, we should keep in mind that radiographic parameters are surrogate endpoints and their clinical relevance remains disputed [36, 37].

There are several strengths to this meta-analysis which include the comprehensive search of the literature and the inclusion of similar trials. Studies in which implants other than volar locking plates, e.g., the fragment-specific wrist fixation system, nonlocking plates or a combination of volar and dorsal plating were used, were not included [14, 20, 38-41]. Similarly, studies using a different form of external fixation and studies with an unclear definition of unstable fractures were excluded as well [20]. Therefore, the results of this meta-analysis will most likely reveal the true magnitude and direction of the differences between the treatments under study.

However, the results of this study should be interpreted with caution because of the following limitations. The power of this meta-analysis was limited since the sample size of the included studies was relatively small. Moreover, the three trials included various AO fracture types and used different definitions of fracture instability and therefore indication for surgery. Finally, unfortunately, only three trials could be included in this analysis. Nevertheless, the quality of a meta-analysis is often considered to be more susceptible to heterogeneity present across studies than the number of included trials [42, 43]. After all, pooled results can be obtained from as few as two studies.

A traditional argument in favor of ORIF with a volar locking plate is early mobilization, which theoretically results in less muscle weakness and therefore improved regain of wrist function. Additionally, the locking principle provides a more rigid construction in the subchondral area of the distal radius, especially in patients with osteoporosis. This theory is in accordance with the results of the current meta-analysis that revealed a significant and clinically relevant improved patient-reported functional outcome for volar locking plate at 3 months. This difference remained significant under a sensitivity analysis and can therefore be considered to be robust. A more rapid recovery might benefit high demanding patients or athletes, and therefore, 
treatment with volar locking plate for these types of patients with an unstable distal radius fracture is recommended.

Acknowledgments No funding was received for this meta-analysis.

Conflict of interest The authors declare that they have no conflict of interest.

Open Access This article is distributed under the terms of the Creative Commons Attribution License which permits any use, distribution, and reproduction in any medium, provided the original author(s) and the source are credited.

\section{References}

1. Singer BR, McLauchlan GJ, Robinson CM, Christie J (1998) Epidemiology of fractures in 15,000 adults: the influence of age and gender. J Bone Joint Surg Br 80(2):243-248

2. Owen RA, Melton LJ 3rd, Johnson KA, Ilstrup DM, Riggs BL (1982) Incidence of Colles' fracture in a North American community. Am J Public Health 72(6):605-607

3. Brogren E, Petranek M, Atroshi I (2007) Incidence and characteristics of distal radius fractures in a southern Swedish region. BMC Musculoskelet Disord 8:48

4. DSo S (2010) Guidelines Distal Radius Fractures, diagnosis and treatment. Anonymous. http://www.nvpc.nl/uploads/stand/Richtlijn_ Distale_radius_fracturen_voor_autorisatiefase_0110201075.pdf

5. Drobetz H, Kutscha-Lissberg E (2003) Osteosynthesis of distal radial fractures with a volar locking screw plate system. Int Orthop 27(1):1-6

6. Slutsky DJ (2005) Nonbridging external fixation of intra-articular distal radius fractures. Hand Clin 21(3):381-394

7. Orbay J (2005) Volar plate fixation of distal radius fractures. Hand Clin 21(3):347-354

8. Hakimi M, Jungbluth P, Windolf J, Wild M (2010) Functional results and complications following locking palmar plating on the distal radius: a retrospective study. J Hand Surg Eur 35(4):283-288

9. Dias JJ, Wray CC, Jones JM, Gregg PJ (1987) The value of early mobilisation in the treatment of Colles' fractures. J Bone Joint Surg Br 69(3):463-467

10. Handoll HH, Huntley JS, Madhok R (2008) Different methods of external fixation for treating distal radial fractures in adults. Cochrane Database Syst Rev 23(1):CD006522

11. Margaliot Z, Haase SC, Kotsis SV, Kim HM, Chung KC (2005) A meta-analysis of outcomes of external fixation versus plate osteosynthesis for unstable distal radius fractures. J Hand Surg Am 30(6): 1185-1199

12. Jupiter JB, Marent-Huber M (2010) Operative management of distal radial fractures with 2.4-millimeter locking plates: a multicenter prospective case series. Surgical technique. J Bone Joint Surg Am 92 Suppl 1 Pt 1:96-106

13. Henry MH (2008) Distal radius fractures: current concepts. J Hand Surg Am 33(7):1215-1227

14. Leung F, Tu YK, Chew WY, Chow SP (2008) Comparison of external and percutaneous pin fixation with plate fixation for intra-articular distal radial fractures. A randomized study. J Bone Joint Surg Am 90(1):16-22

15. Wright TW, Horodyski M, Smith DW (2005) Functional outcome of unstable distal radius fractures: ORIF with a volar fixed-angle tine plate versus external fixation. J Hand Surg Am 30(2):289-299
16. Kvernmo HD, Krukhaug Y (2013) Treatment of distal radius fractures. Tidsskr Nor Laegeforen 133(4):405-411

17. Wei DH, Poolman RW, Bhandari M, Wolfe VM, Rosenwasser MP (2012) External fixation versus internal fixation for unstable distal radius fractures: a systematic review and meta-analysis of comparative clinical trials. J Orthop Trauma 26(7):386-394

18. Beaton DE, Katz JN, Fossel AH, Wright JG, Tarasuk V, Bombardier C (2001) Measuring the whole or the parts? Validity, reliability, and responsiveness of the disabilities of the arm, shoulder and hand outcome measure in different regions of the upper extremity. J Hand Ther 14(2):128-146

19. Schmelzer-Schmied N, Wieloch P, Martini AK, Daecke W (2009) Comparison of external fixation, locking and non-locking palmar plating for unstable distal radius fractures in the elderly. Int Orthop 33(3):773-778

20. Rozental TD, Blazar PE, Franko OI, Chacko AT, Earp BE, Day CS (2009) Functional outcomes for unstable distal radial fractures treated with open reduction and internal fixation or closed reduction and percutaneous fixation. A prospective randomized trial. J Bone Joint Surg Am 91(8):1837-1846

21. Arora R, Gabl M, Gschwentner M, Deml C, Krappinger D, Lutz M (2009) A comparative study of clinical and radiologic outcomes of unstable colles type distal radius fractures in patients older than 70 years: nonoperative treatment versus volar locking plating. J Orthop Trauma 23(4):237-242

22. Arora R, Lutz M, Deml C, Krappinger D, Haug L, Gabl M (2011) A prospective randomized trial comparing nonoperative treatment with volar locking plate fixation for displaced and unstable distal radial fractures in patients sixty-five years of age and older. J Bone Joint Surg Am 93(23):2146-2153

23. Moher D, Liberati A, Tetzlaff J, Altman DG (2010) PRISMA Group. Preferred reporting items for systematic reviews and meta-analyses: the PRISMA statement. Int J Surg 8(5):336-341

24. Atroshi I, Gummesson C, Andersson B, Dahlgren E, Johansson A (2000) The disabilities of the arm, shoulder and hand (DASH) outcome questionnaire: reliability and validity of the Swedish version evaluated in 176 patients. Acta Orthop Scand 71(6):613-618

25. Atkins D, Best D, Briss PA, Eccles M, Falck-Ytter Y, Flottorp S et al (2004) Grading quality of evidence and strength of recommendations. BMJ 328(7454):1490

26. The Nordic Cochrane Centre, The Cochrane Collaboration (2008) Review manager. RevMan 5.0 Anonymous

27. DerSimonian R, Laird N (1986) Meta-analysis in clinical trials. Control Clin Trials 7(3):177-188

28. Higgins JP, Thompson SG (2002) Quantifying heterogeneity in a meta-analysis. Stat Med 21(11):1539-1558

29. Higgins J, Green S (2011) Cochrane handbook for systematic reviews of interventions. Version 5.0.0 edn. The Cochrane Collaboration, Oxford

30. Wei DH, Raizman NM, Bottino CJ, Jobin CM, Strauch RJ, Rosenwasser MP (2009) Unstable distal radial fractures treated with external fixation, a radial column plate, or a volar plate. A prospective randomized trial. J Bone Joint Surg Am 91(7):1568-1577

31. Egol K, Walsh M, Tejwani N, McLaurin T, Wynn C, Paksima N (2008) Bridging external fixation and supplementary Kirschnerwire fixation versus volar locked plating for unstable fractures of the distal radius: a randomised, prospective trial. J Bone Joint Surg Br 90(9):1214-1221

32. Wilcke MK, Abbaszadegan H, Adolphson PY (2011) Wrist function recovers more rapidly after volar locked plating than after external fixation but the outcomes are similar after 1 year. Acta Orthop 82(1):76-81

33. Wei DH, Raizman NM, Bottino CJ, Jobin CM, Strauch RJ, Rosenwasser MP (2009) Unstable distal radial fractures treated with 
external fixation, a radial column plate, or a volar plate. A prospective randomized trial. $\mathrm{J}$ Bone Joint Surg Am 91(7):1568-1577

34. Roy JS, MacDermid JC, Woodhouse LJ (2009) Measuring shoulder function: a systematic review of four questionnaires. Arthritis Rheum 61(5):623-632

35. Beaton DE, Katz JN, Fossel AH, Wright JG, Tarasuk V, Bombardier C (2001) Measuring the whole or the parts? Validity, reliability, and responsiveness of the disabilities of the arm, shoulder and hand outcome measure in different regions of the upper extremity. J Hand Ther 14(2):128-146

36. Bentohami A, Bijlsma TS, Goslings JC, de Reuver P, Kaufmann L, Schep NW (2012) Radiological criteria for acceptable reduction of extra-articular distal radial fractures are not predictive for patient-reported functional outcome. J Hand Surg Eur Vol 38(5):524-529

37. Grewal R, MacDermid JC (2007) The risk of adverse outcomes in extra-articular distal radius fractures is increased with malalignment in patients of all ages but mitigated in older patients. J Hand Surg Am 32(7):962-970

38. Abramo A, Kopylov P, Geijer M, Tagil M (2009) Open reduction and internal fixation compared to closed reduction and external fixation in distal radial fractures: a randomized study of 50 patients. Acta Orthop 80(4):478-485

39. Westphal T, Piatek S, Schubert S, Winckler S (2005) Outcome after surgery of distal radius fractures: no differences between external fixation and ORIF. Arch Orthop Trauma Surg 125(8):507-514

40. Kapoor H, Agarwal A, Dhaon BK (2000) Displaced intra-articular fractures of distal radius: a comparative evaluation of results following closed reduction, external fixation and open reduction with internal fixation. Injury 31(2):75-79

41. Kreder HJ, Hanel DP, Agel J, McKee M, Schemitsch EH, Trumble TE et al (2005) Indirect reduction and percutaneous fixation versus open reduction and internal fixation for displaced intra-articular fractures of the distal radius: a randomised, controlled trial. J Bone Joint Surg Br 87(6):829-836

42. Grobbee DE, Hoes AW (2009) Meta-analysis. Clinical epidemiology, principles, methods, and applications for clinical research Sudbury. Jones and Bartlett Publishers, Massachusetts, pp 288-324

43. Higgins J, Thompson S, Deeks J, Altman D (2002) Statistical heterogeneity in systematic reviews of clinical trials: a critical appraisal of guidelines and practice. J Health Serv Res Policy 7(1):51-61 